\title{
Conscientiousness Is Associated with Lower Risk of Dementia among Black and White Older Adults
}

\author{
Allison R. Kaup ${ }^{a-c}$ Alexandrea L. Harmell ${ }^{b}$ Kristine Yaffe $^{a, b}, d$ \\ ${ }^{a}$ Research Service, San Francisco VA Health Care System, San Francisco, CA, USA; ${ }^{b}$ Mental Health Service, \\ San Francisco VA Health Care System, San Francisco, CA, USA; ' Department of Psychiatry, Weill Institute for \\ Neurosciences, University of California San Francisco, San Francisco, CA, USA; d Department of Neurology and \\ Department of Epidemiology and Biostatistics, University of California San Francisco, San Francisco, CA, USA
}

\section{Keywords}

Personality · Dementia · Conscientiousness ·

Openness to experience

\begin{abstract}
Background: While some personality traits may reduce risk of dementia, this is controversial and has not been studied as much among diverse populations. We examined associations between 2 traits - Conscientiousness and Openness to Experience - and risk of dementia among black and white older adults. Methods: We studied 875 older adults (ages $71-82,47 \%$ black) without prevalent dementia from the Health, Aging and Body Composition study, who completed the NEO Five-Factor Inventory for Conscientiousness and Openness to Experience. Incident dementia over 8 years (mean $=6.9$ years) was determined by hospital records, medications, or $\geq 1.5 \mathrm{SD}$ race-specific decline on the Modified Mini-Mental State Examination. In adjusted models, we investigated associations between each trait and risk of dementia, including for race interactions. Results: Associations between personality traits and dementia risk did not differ by race (interactions: $p>0.7$ ). Higher Conscientiousness was associated with lower dementia risk (adjusted HR per 1SD =
\end{abstract}

(๑) 2019 S. Karger AG, Basel
0.78; 95\% Cl 0.65-0.94). There was no association for Openness to Experience (adjusted HR per $1 \mathrm{SD}=0.88 ; 95 \% \mathrm{Cl} 0.71-$ 1.08). Conclusions: Higher Conscientiousness is associated with lower dementia risk, even among diverse populations. Higher Conscientiousness may be protective, or lower Conscientiousness may be an early symptom of neurodegenerative disease.

(c) 2019 S. Karger AG, Basel

\section{Introduction}

Personality, which describes an individual's consistent pattern of thoughts, feelings, and behavior, influences one's health and lifestyle in a number of ways [1-4]. A growing body of research suggests that some personality traits may influence cognitive health in aging [5]. Older adults who are higher in Neuroticism, a trait characterized by greater vulnerability to stress and negative emotions such as anxiety and depression [6], are more likely develop cognitive decline and dementia [7-9]. Other personality traits might promote resilience against the development of dementia, however this is less well-understood. 
Conscientiousness, a trait characterized by self-control, being responsible, organized, and goal-oriented [6], has been shown to be associated with a variety of positive health outcomes. For example, individuals higher in Conscientiousness engage in more healthy behaviors (e.g., exercise, diet), have better stress coping skills, have less medical illness burden, and tend to live longer [10], raising the possibility that Conscientiousness could have a positive influence on cognitive health in aging as well. Additionally, it is plausible that Openness to Experience could have a protective role against dementia. Individuals with high levels of this trait are more creative, intellectually curious, and interested in seeking out novel experiences [6]. This trait may lead to higher cognitive reserve [11], especially given that engagement in cognitively stimulating activities is thought to build cognitive reserve and reduce risk of dementia [12].

In contrast to the larger number of studies showing a deleterious role of Neuroticism [5], a few studies have investigated associations between Conscientiousness and Openness to Experience with risk of dementia [5]. Moreover, previous research has largely focused on Caucasian older adults [9] and thus it is unclear how these traits relate to risk of dementia in more diverse populations. This is an important limitation, as relationships between personality and other health outcomes differ by race, including between white and black individuals [13, 14], and there are known racial disparities in rates of dementia and other factors that influence dementia risk [15-17].

We investigated associations between Conscientiousness and Openness to Experience with risk of dementia in a cohort of black and white older adults. We hypothesized that higher levels of both of these traits would be associated with reduced risk of dementia, and we specifically aimed to explore for potential racial differences in these relationships.

\section{Methods}

\section{Population}

Participants were from the Health, Aging, and Body Composition (Health ABC) study, a prospective cohort study of community dwelling, black and white older adults conducted in Memphis, Tennessee and Pittsburgh, Pennsylvania [18-21]. Individuals were recruited based on a random sample of white and black Medicareeligible older adults within designated zip codes. To be eligible for enrollment, individuals were required to self-report no difficulty performing activities of daily living, walking a quarter of a mile, or climbing 10 steps without resting, and had no plans to leave the area within 3 years. A total of 3,075 participants were enrolled and they completed their first study visit (year 1) between 1997 and 1998.
A subset of Health ABC participants $(n=951)$ were enrolled in the Health ABC Cognitive Vitality sub-study at year 3, with roughly equal number of participants by race, sex, and site (see additional methods detailed elsewhere [22, 23]). Participants completed a personality inventory at the beginning of the Cognitive Vitality sub-study (our study baseline). We excluded 42 individuals who had missing personality data, as well as an additional 18 individuals who had prevalent dementia, and 16 individuals who did not have follow-up after year 3 . Thus, our analytic cohort consists of 875 participants (ages $71-82,50 \%$ female, $47 \%$ black).

Institutional review boards at the University of Pittsburgh, University of Tennessee, Memphis and University of California, San Francisco approved the study. All participants provided written informed consent.

\section{Measures}

Personality Traits: Conscientiousness and Openness to Experience

Participants completed 2 scales from the NEO Five-Factor Inventory [6] to evaluate the personality traits of Conscientiousness and Openness to Experience (the remaining NEO scales were not included in the Health ABC study). Each scale consists of 12-item with a Likert-based format, with response choices ranging from "Strongly Disagree" (score = 0 ) to "Strongly Agree" (score = 4) and possible total scores ranging from 0 to 48. The NEO Five-Factor Model of personality structure is considered to be universal across diverse racial/ethnic groups $[24,25]$, and its appropriateness for use among older African Americans has been supported [26].

\section{Dementia}

Incident dementia over the following 8 years was determined by a combination of hospital records, prescriptions for dementia medication, or clinically-significant cognitive decline, as was done in previous Health ABC studies [15, 27, 28]. Specifically, every 6 months, participants were asked whether they had been hospitalized, and if so, study staff requested the related hospital records. At each clinic visit, participants were asked to bring their medications with them, and study staff recorded their medication information. Over the course of the study, participants were repeatedly administered the Modified Mini-Mental State Exam (3MS) [29] to assess global cognition at study years $1,3,5,8,10$, and 11 . The $3 \mathrm{MS}$ is a cognitive screening measure, sensitive to dementia [30], that assesses orientation, concentration, language, praxis, and immediate and delayed memory (total score ranges from 0 to 100 points).

An algorithm incorporating the above sources of data was used to determine incident dementia, such that individuals were considered to have dementia if and when they met any of the following criteria: (1) record of hospitalization indicating dementia as a primary or secondary diagnosis; (2) record of a prescription for dementia medication (e.g., galantamine, rivastigmine, memantine, donepezil, tacrine); or (3) clinically significant decline in cognitive functioning (defined as $\geq 1.5 \mathrm{SD}$ race-specific decline in $3 \mathrm{MS}$ score from individuals' baseline to last available visit). The date of dementia onset was considered to be the date at which a participant first met any of the above criteria.

Other Variables

Participants self-reported their age, sex, race, and level of education. Literacy was assessed at year 3 using the Rapid Estimate of Adult Literacy in Medicine, and was coded to reflect $<9$ th grade 
Table 1. Baseline characteristics and bivariate associations with conscientiousness $(n=875)$

\begin{tabular}{|c|c|c|c|c|}
\hline \multirow[t]{2}{*}{ Mean (SD) or $n(\%)$} & \multicolumn{3}{|c|}{ Conscientiousness } & \multirow{2}{*}{$\begin{array}{l}\text { Association with } \\
\text { conscientiousness } \\
\text { (continuous score), } \\
p \text { value }\end{array}$} \\
\hline & $\begin{array}{l}>1 S D \text { below } \\
\text { mean }(n=143)\end{array}$ & $\begin{array}{l}\text { mean } \pm 1 S D \\
(n=624)\end{array}$ & $\begin{array}{l}>1 S D \text { above } \\
\text { mean }(n=108)\end{array}$ & \\
\hline Age, years & $75.3(2.8)$ & $75.2(2.7)$ & $75.1(2.8)$ & 0.19 \\
\hline Female & 49.7 & 49.7 & 54.6 & 0.54 \\
\hline Black & 44.1 & 47.4 & 50.0 & 0.26 \\
\hline \multicolumn{5}{|l|}{ Education } \\
\hline$<$ High school & 23.1 & 21.3 & 14.8 & \multirow[t]{3}{*}{$0.003^{*}$} \\
\hline HS/some college & 55.2 & 49.9 & 49.1 & \\
\hline > Bachelor's degree & 21.7 & 28.8 & 36.1 & \\
\hline Literacy, $\geq 9$ th grade & 75.5 & 75.0 & 75.9 & 0.91 \\
\hline Hypertension & 70.6 & 71.2 & 70.4 & 0.46 \\
\hline Myocardial infarction & 15.4 & 15.9 & 15.7 & 0.19 \\
\hline Diabetes & 26.8 & 18.1 & 16.7 & 0.05 \\
\hline Stroke/TIA & 10.6 & 7.3 & 8.4 & 0.40 \\
\hline Obesity & 28.9 & 20.7 & 24.3 & 0.66 \\
\hline Current smoker & 7.7 & 5.3 & 5.6 & 0.58 \\
\hline Apolipoprotein E e4 & 31.6 & 28.9 & 30.0 & 0.67 \\
\hline Depressive symptoms & $5.3(4.2)$ & $3.8(3.6)$ & $3.0(3.2)$ & $<0.001^{*}$ \\
\hline
\end{tabular}

* Statistically significant $(p<0.05)$.

versus $\geq 9$ th grade reading level [31]. The presence of cardiovascular comorbidities at year 3 , including hypertension, myocardial infarction, diabetes, and stroke/transient ischemic attack (TIA), were determined via a combination of physician diagnosis, medications, laboratory values, and self-report. Obesity was defined as body mass index $>30 \mathrm{~kg} / \mathrm{m}^{2}$, as calculated from height and weight measurements. Depressive symptoms were assessed using the Center for Epidemiologic Studies Depression Scale Short Form (CES-D-10) [32], a 10-item inventory (score from 0 to 30, with higher scores indicating higher depressive symptoms and score $\geq 10$ suggesting depression [32]. Current cigarette smoking was determined by self-report. Apolipoprotein E genotyping was completed using standard single nucleotide polymorphism analyses.

\section{Statistical Analysis}

We first examined distributions of the personality scores and conducted $t$ test and correlation analyses to investigate bivariate associations between each personality trait and participant characteristics. Using Cox proportional hazard models, we investigated the association between each personality trait and risk of dementia, including personality trait $\times$ race interaction terms to test whether associations differed by race. Models adjusted for demographics, site, education, literacy, and depressive symptoms, as well as other health factors associated $(p<0.10)$ with either personality trait. In our analyses, we treated the personality trait measures as continuous variables. For descriptive purposes, we categorized individuals into 3 groups based their personality trait scores reflecting those whose score fell $>1$ SD below mean, within \pm 1 SD from the mean, or $>1 S D$ above mean for use in tables and figures. Statistical analyses were conducted using SAS software, version 9.4 (SAS Institute Inc., Cary, NC, USA) and Stata, version 14 [33]. Statistical significance was set at $p<0.05$ (two-tailed).

\section{Results}

Mean Conscientiousness and Openness to Experience scores were $33.6(\mathrm{SD}=5.5$, range $11-48)$ and $24.8(\mathrm{SD}=$ 5.4 , range 10-42), respectively, and scores were normally distributed in both black and white older adults. Conscientiousness score did not differ by race (whites: mean $=33.4$, $\mathrm{SD}=5.6$; blacks: $33.8, \mathrm{SD}=5.4 ; p=0.26$ ). Openness to Experience score was slightly lower in blacks (mean $=24.1$, $\mathrm{SD}=4.9)$ compared to whites (mean $=25.5, \mathrm{SD}=5.7 ; p<$ 0.001 ).

Associations between Conscientiousness and other participant characteristics are shown in Table 1. Individuals with higher Conscientiousness were more highly educated $(p=0.003)$ and had fewer depressive symptoms $(p<0.001)$, and tended to have less diabetes $(p=0.05)$, while all other associations were non-significant. As shown in online supplementary Table 1 (see www.karger. com/doi/10.1159/000492821), higher Openness to Experience was associated with female gender, higher education and literacy, and lower depressive symptoms (all $p<$ $0.05)$. Several cardiovascular conditions were more common in those with lower Openness to Experience, including hypertension, myocardial infarction, and diabetes (all $p<0.05)$; with a similar trend for stroke/TIA $(p=0.06)$.

Of the total 875 participants, $14.3 \%(n=125)$ developed dementia over 8 years of study follow-up (mean follow-up 


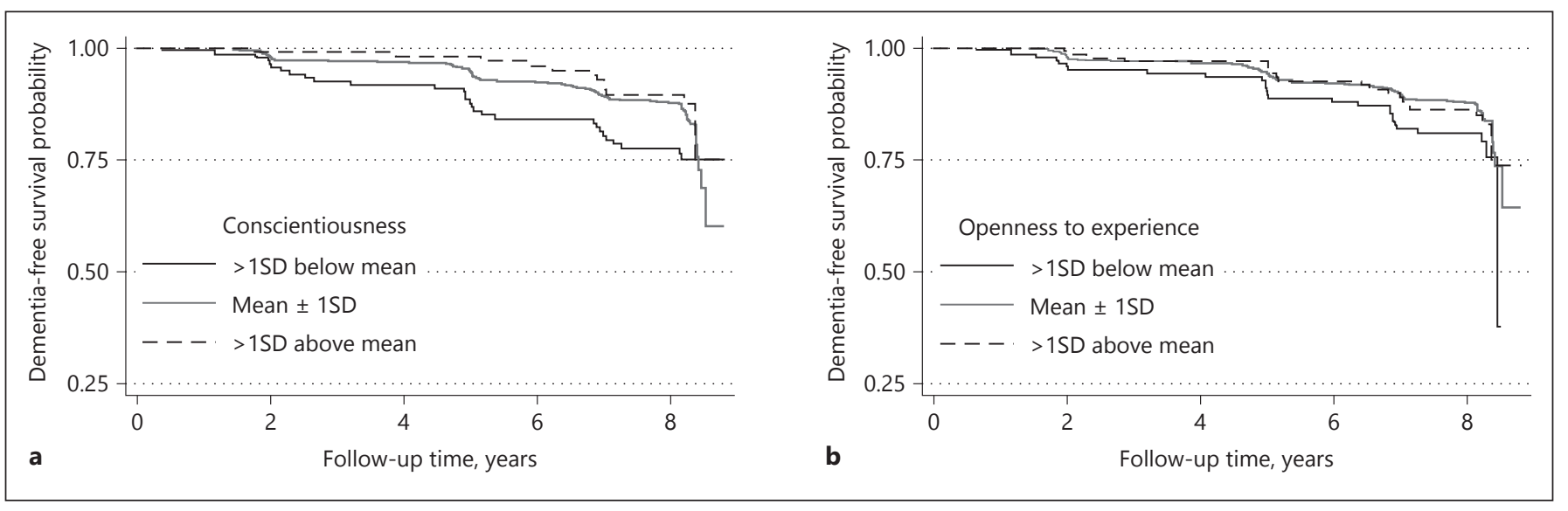

Fig. 1. Association between Personality Traits and Dementia-Free Survival in 875 Black and White Older Adults (Kaplan-Meier Survival Curves). Kaplan-Meier Survival Curves showing probability of dementia-free survival by level of each personality trait ([a] con-

for dementia $=6.9$ years, $\mathrm{SD}=2.2)$, including $16.2 \%(n=67)$ of black individuals and $12.6 \%(n=58)$ of white individuals. In Cox proportional hazard models investigating associations between each personality trait and incident dementia, personality trait $\times$ race interaction terms were non-significant (Conscientiousness $\times$ race: $p=0.76$; Openness $\times$ race: $p=0.91$ ), indicating that associations did not differ by race. Therefore, we combined both race groups for final models. Figure 1 shows Kaplan-Meier survival curves depicting dementia incidence by each personality trait among black and white older adults. Older adults with higher Conscientiousness were less likely to develop dementia in unadjusted (unadjusted HR 0.75 per 1SD in Conscientiousness [95\% CI 0.64-0.89]) and adjusted Cox proportional hazard models (adjusted HR 0.78 per 1SD in Conscientiousness [95\% CI 0.65-0.94], adjusted for age, sex, race, education, literacy, site, depressive symptoms, hypertension, myocardial infarction, diabetes, and stroke/TIA). However, there was no association between Openness to Experience and risk of dementia (unadjusted HR 0.89 per 1SD in Openness [95\% CI $0.74-1.06$ ]; adjusted HR 0.88 per 1 SD in Openness [95\% CI 0.71-1.08], adjusted for age, sex, race, education, literacy, site, depressive symptoms, hypertension, myocardial infarction, diabetes, and stroke/TIA).

\section{Discussion}

Among black and white older adults followed over 8 years, we investigated associations between the personality traits of Conscientiousness and Openness to Experi- scientiousness, [b] openness to experience). For descriptive purposes, individuals were categorized into 3 groups based on their personality trait score, reflecting score $>1$ SD below mean, mean \pm $1 S D$, or $>1 S D$ above mean.

ence and risk of dementia. Although we found no association between Openness to Experience and incident dementia, older adults with higher levels of Conscientiousness, including both black and white individuals, were less likely to develop dementia. These results build on the broader literature suggesting some personality traits have positive impacts on cognitive outcomes in aging. Our finding of a beneficial role of Conscientiousness in particular is similar to results from prior research among predominantly white older adult cohorts, $[8,34]$ and extends understanding of this relationship by showing that it is universal across black and white individuals.

There are several possible mechanisms that may contribute to the association between Conscientiousness and dementia risk. Conscientiousness may be a protective trait that promotes healthy brain aging. Individuals high in Conscientiousness may be more likely to engage in healthy behaviors such as exercising, eating a healthy diet, having regular check-ups with their doctors, and adhering to treatment recommendations $[35,36]$. Such healthpromoting behaviors, like exercise, may have direct positive effects on brain health [37]. Healthy lifestyle behaviors may also help prevent the development of medical conditions known to increase risk for dementia, like cardiovascular disease [38]. Conversely, individuals with lower Conscientiousness have been shown to engage in more risky health behaviors like substance use $[39,40]$, as well as to have poorer sleep [41], which impacts cognition in older adulthood [42]. However, in the present study, we examined several health factors as potential covariates and found few associations between Conscientiousness 
and these factors in our cohort, suggesting that healthrelated mechanisms driving the association between Conscientiousness and risk of dementia extend beyond the covariates we examined.

Another mechanism linking Conscientiousness to reduced risk for dementia could be this trait's relationship with achievement, which may in turn contribute to higher cognitive reserve. For example, higher Conscientiousness has been shown to influence individuals to achieve higher educational and occupational status [35, 43], which are factors thought to build cognitive reserve [12] and protect against cognitive decline and dementia in older adulthood $[44,45]$. Relatedly, evidence from neuroimaging and neuropathology studies supports that Conscientiousness promotes brain health and resilience against dementia. In a study [46] employing diffusion tensor imaging, older adults with higher Conscientiousness were found to have greater white matter tract-specific fractional anisotropy in multiple regions, suggesting this trait may promote white matter integrity. A study examining associations between premorbid personality traits and Alzheimer's disease (AD) neuropathology at autopsy found that older adults who had asymptomatic $\mathrm{AD}$ (i.e., those positive for $\mathrm{AD}$ neuropathology but free of dementia) had been higher in Conscientiousness compared to those with symptomatic AD (i.e., those with Alzheimer's dementia), suggesting that Conscientiousness promotes resilience in enabling individuals to avoid manifesting the clinical symptoms of $\mathrm{AD}$ despite presence of neuropathology [47]. How personality traits, like Conscientiousness, contribute to cognitive reserve and resilience warrants further exploration. Mechanisms may be complex and not straightforward. Indeed, it is somewhat surprising we did not find an association between Openness to Experience and risk of dementia, as that trait is similarly associated with factors thought to contribute to cognitive reserve (higher educational and occupational attainment) [35, 43].

While a protective role of Conscientiousness is possible, an alternative explanation for our findings is that low Conscientiousness may be an early symptom of an underlying neurodegenerative disease process. Although personality traits are generally considered to remain stable across adulthood [48], personality changes can occur among patients with dementia and may even emerge during earlier stages of the neurodegenerative disease process [49-51]. It is possible that older adults just beginning to exhibit subtle cognitive and brain changes may also begin experiencing diminished ability to maintain personal qualities and behaviors that define
Conscientiousness, such as reduced ability to stay organized and achieve goals. Although a strength of our study is that older adults were followed for incident dementia several years after completing the personality measures, it is possible that at least some individuals in our study who had low Conscientiousness scores at study baseline could have already been in the pre-clinical stages of an insidious neurodegenerative disease like $\mathrm{AD}[52]$.

Additional limitations of this study include that incident dementia was determined based on an algorithm rather than a clinical diagnosis; therefore, some misclassification may be possible. Finally, we were unable to investigate the role of other personality traits which were not measured in the Health ABC study.

Although personality traits have received less attention than other established contributors to dementia risk (e.g., genetics, neuroimaging markers, physical health factors, education), our study suggests that the personality trait of Conscientiousness also plays an important role. Additional longitudinal studies, ideally with repeated measurement of personality, cognition, and brain changes, are needed to clarify the extent to which high Conscientiousness may be a protective factor versus the possibility that low Conscientiousness may be an early symptom of neurodegenerative disease. Clarification of this relationship may inform implications for dementia screening or prevention efforts. In addition to evaluating whether older patients have other dementia risk factors, screening for low Conscientiousness may provide added value in attempts to identify older adults who are likely to be at high risk for dementia. To the extent that Conscientiousness may play a protective role in supporting brain health and resilience in aging, additional research is needed to clarify if and how Conscientiousness could be incorporated in dementia prevention and intervention efforts.

\section{Acknowledgments}

This research was supported by National Institute on Aging (NIA) Contracts N01-AG-6-2101; N01-AG-6-2103; N01AG-6-2106; NIA grant R01-AG028050, and NINR grant R01NR012459. This research was supported in part by the Intramural Research Program of the NIH, National Institute on Aging. Dr. Kaup is supported by Career Development Award 1IK2RX001629 from the U.S. Department of Veterans Affairs, Rehabilitation Research and Development Service (the contents of this manuscript do not represent the views of the U.S. Department of Veterans Affairs or the United States Government). Support was also provided by NIA grant K24AG031155, awarded to Dr. Kristine Yaffe.
90

Neuroepidemiology 2019;52:86-92 DOI: $10.1159 / 000492821$
Kaup/Harmell/Yaffe 


\section{References}

1 Friedman HS: Long-term relations of personality and health: dynamisms, mechanisms, tropisms. J Pers 2000;68:1089-1107.

2 Turiano NA, Pitzer L, Armour C, Karlamangla A, Ryff CD, Mroczek DK: Personality trait level and change as predictors of health outcomes: findings from a national study of americans (MIDUS). J Gerontol B Psychol Sci Soc Sci 2011;67:4-12.

3 Connor-Smith JK, Flachsbart C: Relations between personality and coping: a meta-analysis. J Pers Soc Psychol 2007;93:1080.

4 Sutin AR, Stephan Y, Luchetti M, Artese A, Oshio A, Terracciano A: The five-factor model of personality and physical inactivity: a meta-analysis of 16 samples. J Res Pers 2016;63: 22-28.

5 Low LF, Harrison F, Lackersteen SM: Does personality affect risk for dementia? A systematic review and meta-analysis. Am J Geriatr Psychiatry 2013;21:713-728.

6 Costa PT, MacCrae RR: Revised Neo Personality Inventory (neo pi-r) and Neo Five-Factor Inventory (neo-ffi): Professional Manual. Psychological Assessment Resources, Incorporated, 1992.

7 Chapman B, Duberstein P, Tindle HA, Sink KM, Robbins J, Tancredi DJ, Franks P; Gingko Evaluation of Memory Study Investigators: Personality predicts cognitive function over 7 years in older persons. Am J Geriatr Psychiatry 2012;20:612-621.

8 Duberstein PR, Chapman BP, Tindle HA, Sink KM, Bamonti P, Robbins J, Jerant AF, Franks P: Personality and risk for Alzheimer's disease in adults 72 years of age and older: a 6-year follow-up. Psychol Aging 2011;26:351.

9 Terracciano A, Sutin AR, An Y, O'Brien RJ, Ferrucci L, Zonderman AB, Resnick SM: Personality and risk of Alzheimer's disease: new data and meta-analysis. Alzheimers Dement 2014;10:179-186.

10 Bogg T, Roberts BW: The case for conscientiousness: evidence and implications for a personality trait marker of health and longevity. Ann Behav Med 2013;45:278-288.

11 Sharp ES, Reynolds CA, Pedersen NL, Gatz $\mathrm{M}$ : Cognitive engagement and cognitive aging: is openness protective? Psychol Aging 2010;25:60.

12 Stern Y: Cognitive reserve in ageing and $\mathrm{Al}-$ zheimer's disease. Lancet Neurol 2012;11: 1006-1012.

13 Jonassaint CR, Boyle SH, Kuhn CM, Siegler IC, Copeland WE, Williams R: Personality and inflammation: the protective effect of openness to experience. Ethn Dis 2010;20:1114.

14 Krok-Schoen JL, Baker TA: Race differences in personality and affect between older white and black patients: an exploratory study. J Racial Ethn Health Disparities 2014;1:283-290.

15 Yaffe K, Falvey C, Harris TB, Newman A, Satterfield S, Koster A, Ayonayon H, Simonsick E: Effect of socioeconomic disparities on incidence of dementia among biracial older adults: prospective study. BMJ 2013;347: f7051.

16 Kaup AR, Nettiksimmons J, Harris TB, Sink KM, Satterfield S, Metti AL, Ayonayon HN, Yaffe K: Cognitive resilience to apolipoprotein $\mathrm{E} \varepsilon 4$ : contributing factors in black and white older adults. JAMA Neurol 2015;72: 340-348.

17 Mayeda ER, Glymour MM, Quesenberry CP, Whitmer RA: Inequalities in dementia incidence between six racial and ethnic groups over 14 years. Alzheimers Dement 2016;12: 216-224.

18 Harris TB, Visser M, Everhart J, Cauley J, Tylavsky F, Fuerst T, Zamboni M, Taaffe D, Resnick HE, Scherzinger A, Nevitt M: Waist circumference and sagittal diameter reflect total body fat better than visceral fat in older men and women. The health, aging and body composition study. Ann N Y Acad Sci 2000; 904:462-473.

19 Rooks RN, Simonsick EM, Miles T, Newman A, Kritchevsky SB, Schulz R, Harris T: The association of race and socioeconomic status with cardiovascular disease indicators among older adults in the health, aging, and body composition study. J Gerontol B Psychol Sci Soc Sci 2002;57:S247-S256.

20 Yaffe K, Barnes D, Lindquist K, Cauley J, Simonsick EM, Penninx B, Satterfield S, Harris T, Cummings SR: Endogenous sex hormone levels and risk of cognitive decline in an older biracial cohort. Neurobiol Aging 2007;28: 171-178.

21 Yaffe K, Fiocco AJ, Lindquist K, Vittinghoff E, Simonsick EM, Newman AB, Satterfield S, Rosano C, Rubin SM, Ayonayon HN: Predictors of maintaining cognitive function in older adults: the health abc study. Neurology 2009;72:2029-2035.

22 Watson NL, Sutton-Tyrrell K, Rosano C, Boudreau RM, Hardy SE, Simonsick EM, Najjar SS, Launer LJ, Yaffe K, Atkinson HH, Satterfield S, Newman AB: Arterial stiffness and cognitive decline in well-functioning older adults. J Gerontol A Biol Sci Med Sci 2011; 1336-1342.

23 Watson N, Rosano C, Boudreau R, Simonsick E, Ferrucci L, Sutton-Tyrrell K, Hardy S, Atkinson H, Yaffe K, Satterfield S: Executive function, memory, and gait speed decline in well-functioning older adults. J Gerontol A Biol Sci Med Sc 2010;65:1093-1100.

24 Schmitt DP, Allik J, McCrae RR, BenetMartínez V: The geographic distribution of big five personality traits: patterns and profiles of human self-description across 56 nations. J Cross Cultural Psychol 2007;38: 173-212.

25 McCrae RR: Cross-cultural research on the five-factor model of personality. Online Read Psychol Culture 2002;4:1.

26 Savla J, Davey A, Costa PT, Whitfield KE: Replicating the neo-pi-r factor structure in
African-American older adults. Pers Individual Differ 2007;43:1279-1288.

27 Hong CH, Falvey C, Harris TB, Simonsick EM, Satterfield S, Ferrucci L, Metti AL, Patel $\mathrm{KV}$, Yaffe K: Anemia and risk of dementia in older adults: findings from the health $\mathrm{ABC}$ study. Neurology 2013;81:528-533.

28 Kaup AR, Simonsick EM, Harris TB, Satterfield S, Metti AL, Ayonayon HN, Rubin SM, Yaffe K: Older adults with limited literacy are at increased risk for likely dementia. J Gerontol A Biol Sci Med Sci 2014;69:900-906.

29 Teng EL, Chui HC: The modified mini-mental state (3MS) examination. Can J Psychiatry 1987;41:114-121.

30 Holsinger T, Plassman BL, Stechuchak KM, Burke JR, Coffman CJ, Williams JW Jr: Screening for cognitive impairment: comparing the performance of four instruments in primary care. J Am Geriatr Soc 2012;60:10271036.

31 Davis TC, Long SW, Jackson RH, Mayeaux EJ, George RB, Murphy PW, Crouch MA: Rapid estimate of adult literacy in medicine: a shortened screening instrument. Fam Med 1993;25:391-395.

32 Andresen EM, Malmgren JA, Carter WB, Patrick DL: Screening for depression in well older adults: Evaluation of a short form of the CES-D (Center for Epidemiologic Studies Depression Scale). Am J Prev Med 1994;10: 77-84.

33 StataCorp: Stata: Release 14. College Station, TX, StataCorp LP, 2015, pp Statistical Software.

34 Wilson RS, Schneider JA, Arnold SE, Bienias JL, Bennett DA: Conscientiousness and the incidence of alzheimer disease and mild cognitive impairment. Arch Gen Psychiatry 2007;64:1204-1212.

35 Hampson SE, Goldberg LR, Vogt TM, Dubanoski JP: Mechanisms by which childhood personality traits influence adult health status: educational attainment and healthy behaviors. Health Psychol 2007;26: 121.

36 Lodi-Smith J, Jackson J, Bogg T, Walton K, Wood D, Harms P, Roberts BW: Mechanisms of health: education and health-related behaviours partially mediate the relationship between conscientiousness and self-reported physical health. Psychol Health 2010;25:305319.

37 Voss MW, Nagamatsu LS, Liu-Ambrose T, Kramer AF: Exercise, brain, and cognition across the life span. J Appl Physiol 2011;111: 1505-1513.

38 Barnes DE, Yaffe K: The projected effect of risk factor reduction on Alzheimer's disease prevalence. Lancet Neurol 2011;10:819828

39 Walton KE, Roberts BW: On the relationship between substance use and personality traits: abstainers are not maladjusted. J Res Pers 2004;38:515-535. 
40 Terracciano A, Löckenhoff CE, Crum RM, Bienvenu OJ, Costa PT Jr: Five-factor model personality profiles of drug users. BMC Psychiatry 2008;8:22.

41 Duggan KA, Friedman HS, McDevitt EA, Mednick SC: Personality and healthy sleep: The importance of conscientiousness and neuroticism. PLoS One 2014;9:e90628.

42 Yaffe K, Falvey CM, Hoang T: Connections between sleep and cognition in older adults. Lancet Neurol 2014;13:1017-1028.

43 Cheng H, Furnham A: Childhood cognitive ability, education, and personality traits predict attainment in adult occupational prestige over 17 years. J Vocational Behav 2012;81:218-226.

44 Meng X, D'Arcy C: Education and dementia in the context of the cognitive reserve hypothesis: a systematic review with meta-analyses and qualitative analyses. PLoS One 2012;7: e38268.
45 Pool LR, Weuve J, Wilson RS, Bültmann U, Evans DA, Mendes de Leon CF: Occupational cognitive requirements and late-life cognitive aging. Neurology 2016;86:1386-1392.

46 Lewis GJ, Cox SR, Booth T, Muñoz Maniega S, Royle NA, Valdés Hernández M, Wardlaw JM, Bastin ME, Deary IJ: Trait conscientiousness and the personality meta-trait stability are associated with regional white matter microstructure. Soc Cogn Affect Neurosci 2016; 11:1255-1261.

47 Terracciano A, Iacono D, O'Brien RJ, Troncoso JC, An Y, Sutin AR, Ferrucci L, Zonderman $A B$, Resnick SM: Personality and resilience to Alzheimer's disease neuropathology: a prospective autopsy study. Neurobiol Aging 2013;34:1045-1050.

48 Ferguson CJ: A meta-analysis of normal and disordered personality across the life span. Am Psychol Assoc 2010;98:659-667.
49 Balsis S, Carpenter BD, Storandt M: Personality change precedes clinical diagnosis of dementia of the alzheimer type. J Gerontol B Psychol Sci Soc Sci 2005;60:P98-P101.

50 Robins Wahlin TB, Byrne GJ: Personality changes in Alzheimer's disease: a systematic review. Int J Geriatr Psychiatry 2011;26:10191029.

51 Terracciano A, Stephan Y, Luchetti M, Sutin AR: Cognitive impairment, dementia, and personality stability among older adults. Assessment 2018;25:336-347.

52 Sperling RA, Aisen PS, Beckett LA, Bennett DA, Craft S, Fagan AM, Iwatsubo T, Jack CR Jr, Kaye J, Montine TJ: Toward defining the preclinical stages of Alzheimer's disease: recommendations from the national institute on aging-Alzheimer's association workgroups on diagnostic guidelines for Alzheimer's disease. Alzheimers Dementia 2011;7:280-292. 